\title{
Spectrum-effect relationship between serum HPLC fingerprints and activation of blood circulation and removal of blood stasis by Chuanxiong
}

\author{
Ling Chen, Wei Deng, Shirong Liu, Fengchao Li, Huimin Li, Guihua Jiang* \\ College of Pharmacy, Chengdu University of Traditional Chinese Medicine, No. 1166 Liutai Avenue, Wenjiang District, \\ Chengdu, 611137, China
}

*For correspondence: Email: 11469413@qq.com; Tel: +86 18980923782

Sent for review: 26 November 2020

Revised accepted: 20 March 2021

\begin{abstract}
Purpose: To study the active ingredients of Chuanxiong (CX) in promoting blood circulation and removing blood stasis.

Methods: Blood-activating effects and serum HPLC fingerprints of CX extracts from different parts of China were studied and the spectrum-effect relationship between them was established by grey correlation analysis.

Results: After treatment with CX extracted using different solvents, hemorheology indices were lower than those in the model group, and the effect of dichloromethane was better than that of other solvents $(p<0.05$ or $p<0.01)$. There were 6 common peaks by fingerprint analysis. Peaks $1-5$ were identified as senkyunolide $I$, senkyunolide $H$, senkyunolide $A$, coniferyl ferulate and ligustilide, respectively.

Conclusion: Analysis of the spectrum-effect relationship indicates the contribution of the five components to the blood-activating effect of CX. The findings lend some scientific justification for using CX to remove blood stasis, and selection of quality evaluation indices for CX.
\end{abstract}

Keywords: Chuanxiong, Blood-activating, Dichloromethane, Serum fingerprint, Senkyunolide I, Senkyunolide $H$, Senkyunolide A, Coniferyl ferulate, Ligustilide

\begin{abstract}
This is an Open Access article that uses a fund-ing model which does not charge readers or their institutions for access and distributed under the terms of the Creative Commons Attribution License (http://creativecommons.org/licenses/by/4.0) and the Budapest Open Access Initiative (http://www.budapestopenaccessinitiative.org/read), which permit unrestricted use, distribution, and reproduction in any medium, provided the original work is properly credited.
\end{abstract}

Tropical Journal of Pharmaceutical Research is indexed by Science Citation Index (SciSearch), Scopus, International Pharmaceutical Abstract, Chemical Abstracts, Embase, Index Copernicus, EBSCO, African Index Medicus, JournalSeek, Journal Citation Reports/Science Edition, Directory of Open Access Journals (DOAJ), African Journal Online, Bioline International, Open-J-Gate and Pharmacy Abstracts

\section{INTRODUCTION}

Chuanxiong $(\mathrm{CX})$ is the dried rhizome of Ligusticum chuanxiong Hort. CX is a well-known plant used in traditional Chinese medicine (TCM) formulations which activates the blood circulation and relieves pain [1]. Usually, it is employed with Angelica sinensis radix and Salvia miltiorrhiza for the treatment of irregular menstruation, migraine, coronary heart disease, and angina [2-4]. The main chemical components of $\mathrm{CX}$ are volatile oils, alkaloids, organic acids and phenols.

According to TCM theory, if the blood is clear, then pain will be absent. Studies on the pharmacodynamic basis of the effects of $\mathrm{CX}$ have focused primarily on chuanxiongzine, ferulic acid, ligustilide and senkyunolide with little or no chuanxiongzine in the original CX or CX extracts. Studies [5-7] have shown that the main components in the plasma of rats after $\mathrm{CX}$ 
administration are ferulic acid, ligustilide and senkyunolide, but chuanxiongzine is absent. $\mathrm{Li}$ and colleagues [8] showed that endoesters were the main active ingredients of $\mathrm{CX}$, and that $\mathrm{CX}$ had a good effect on ischemic cardiac disease and cerebrovascular disease. Hence, the identity of the main components of $\mathrm{CX}$ that have pharmacodynamic effects is not known.

We investigated the active ingredients of $\mathrm{CX}$ that promote blood circulation and remove blood stasis. The aim of the study was to determine the "spectrum-effect relationship" between serum high-performance liquid chromatography (HPLC), as well as the effect of $\mathrm{CX}$ on blood circulation and removal of blood stasis by grey correlation analyses.

\section{EXPERIMENTAL}

\section{Ethical approval of the study protocol}

Animal experiments were undertaken with the approval of the Ethics Committee of Chengdu University of Traditional Chinese Medicine (Chengdu, China). Animal treatments were conducted in strict compliance with the Guide for the Care and Use of Laboratory Animals (US
National Institutes of Health, Bethesda, MD, USA) [11].

\section{Materials}

Twenty-two batches of CX were collected from major producing areas in Sichuan Province, one batch of CX was collected from Fujian Province, and one batch of $\mathrm{CX}$ was collected from Shanxi Province, in China, and identified by Professor Yu-Ying $\mathrm{Ma}$ and Professor Gui-Hua Jiang (College of Pharmacy, Chengdu University of TCM, Chengdu, China). Information on these 24 batches of $\mathrm{CX}$ is shown in Table 1 .

HPLC was carried out on a LC-2012 system (Shimadzu, Kyoto, Japan). An automatic hemorrheometer (SA-6000; Succeeder, Beijing, China) was used to assay blood samples. Methanol (HPLC - grade) was obtained from Thermo Fisher Scientific (Waltham, MA, USA). Ethanol, petroleum ether, dichloromethane, ethyl acetate, N-butanol, and picric acid were purchased from Chengdu Kelong Chemical Reagents (Chengdu, China). Z-ligustilide, levistilide $A$, senkyunolide $I$, senkyunolide $A$, coniferyl ferulate, and senkyunolide $\mathrm{H}$ were obtained from Chroma Biotechnology (Chengdu, China), and their purity was $>95 \%$.

Table 1 : Information on chuanxiong batches

\begin{tabular}{|c|c|c|c|c|c|}
\hline $\begin{array}{l}\text { Batch } \\
\text { number }\end{array}$ & $\begin{array}{l}\text { Place of } \\
\text { production }\end{array}$ & Altitude & Latitude (E) & Longitude (N) & $\begin{array}{l}\text { Time of } \\
\text { collection }\end{array}$ \\
\hline CX1 & Meishan, Sichuan & 427.0 & $103^{\circ} 38^{\prime} 10.7^{\prime \prime}$ & $30^{\circ} 03^{\prime} 25.1^{\prime \prime}$ & 2017.04 \\
\hline $\mathrm{CX} 2$ & Meishan, Sichuan & 412.0 & $103^{\circ} 45^{\prime} 05.2^{\prime \prime}$ & $30^{\circ} 05^{\prime} 11.4^{\prime \prime}$ & 2017.04 \\
\hline CX3 & Meishan, Sichuan & 383.0 & $103^{\circ} 52^{\prime} 15.9^{\prime \prime}$ & $29^{\circ} 54^{\prime} 44.9^{\prime \prime}$ & 2017.04 \\
\hline CX4 & Meishan, Sichuan & 395.0 & $103^{\circ} 50^{\prime} 30.9^{\prime \prime}$ & $29^{\circ} 57^{\prime} 05.1^{\prime \prime}$ & 2017.04 \\
\hline $\mathrm{CX} 5$ & Meishan, Sichuan & 438.0 & $103^{\circ} 45^{\prime} 19.5^{\prime \prime}$ & $30^{\circ} 11^{\prime} 46.8^{\prime \prime}$ & 2017.04 \\
\hline $\mathrm{CX} 6$ & Meishan, Sichuan & 426.0 & $103^{\circ} 43^{\prime} 49.4^{\prime \prime}$ & $30^{\circ} 08^{\prime} 20.8^{\prime \prime}$ & 2017.04 \\
\hline $\mathrm{CX} 7$ & Meishan, Sichuan & 444.0 & $103^{\circ} 47^{\prime} 18.2^{\prime \prime}$ & $30^{\circ} 28^{\prime} 43.8^{\prime \prime}$ & 2017.04 \\
\hline $\mathrm{CX8}$ & Meishan, Sichuan & 442.0 & $103^{\circ} 47^{\prime} 57.5^{\prime \prime}$ & $30^{\circ} 14^{\prime} 55.2^{\prime \prime}$ & 2017.04 \\
\hline CX9 & Meishan, Sichuan & 427.0 & $103^{\circ} 49^{\prime} 22.9^{\prime \prime}$ & $30^{\circ} 12^{\prime} 36.3^{\prime \prime}$ & 2017.04 \\
\hline CX10 & Shifang, Sichuan & 533.0 & $104^{\circ} 05^{\prime} 55.5^{\prime \prime}$ & $31^{\circ} 05^{\prime} 36.1^{\prime \prime}$ & 2017.04 \\
\hline CX11 & Shifang, Sichuan & 530.0 & $104^{\circ} 05^{\prime} 54.0^{\prime \prime}$ & $31^{\circ} 08^{\prime} 27.0^{\prime \prime}$ & 2017.04 \\
\hline CX12 & Pengzhou, Sichuan & 674.0 & $103^{\circ} 54^{\prime} 48.3^{\prime \prime}$ & $31^{\circ} 05^{\prime} 31.2^{\prime \prime}$ & 2017.05 \\
\hline CX13 & Pengzhou, Sichuan & 604.0 & $103^{\circ} 58^{\prime} 10.3^{\prime \prime}$ & $31^{\circ} 08^{\prime} 14.4^{\prime \prime}$ & 2017.05 \\
\hline CX14 & Pengzhou, Sichuan & 604.0 & $103^{\circ} 59^{\prime} 53.1^{\prime \prime}$ & $31^{\circ} 07^{\prime} 56.7^{\prime \prime}$ & 2017.05 \\
\hline CX15 & Pengzhou, Sichuan & 599.0 & $103^{\circ} 59^{\prime} 38.7^{\prime \prime}$ & $31^{\circ} 06^{\prime} 40.3^{\prime \prime}$ & 2017.05 \\
\hline CX16 & Pengzhou, Sichuan & 590.0 & $103^{\circ} 59^{\prime} 23.3^{\prime \prime}$ & $31^{\circ} 03^{\prime} 08.5^{\prime \prime}$ & 2017.05 \\
\hline CX17 & Pengzhou, Sichuan & 568.0 & $104^{\circ} 00^{\prime} 57.8^{\prime \prime}$ & $31^{\circ} 01^{\prime} 03.1^{\prime \prime}$ & 2017.05 \\
\hline CX18 & Xindu, Sichuan & 542.0 & $103^{\circ} 59^{\prime} 46.8^{\prime \prime}$ & $30^{\circ} 53^{\prime} 59.6^{\prime \prime}$ & 2017.05 \\
\hline CX19 & $\begin{array}{l}\text { Dujiangyan, } \\
\text { Sichuan }\end{array}$ & 626.0 & $103^{\circ} 39^{\prime} 14.5^{\prime \prime}$ & $30^{\circ} 49^{\prime} 48.5^{\prime \prime}$ & 2017.05 \\
\hline CX20 & $\begin{array}{l}\text { Dujiangyan, } \\
\text { Sichuan }\end{array}$ & 592.0 & $103^{\circ} 40^{\prime} 21.5^{\prime \prime}$ & $30^{\circ} 46^{\prime} 38.8^{\prime \prime}$ & 2017.05 \\
\hline $\mathrm{CX} 21$ & $\begin{array}{l}\text { Dujiangyan, } \\
\text { Sichuan }\end{array}$ & 626.0 & $103^{\circ} 40^{\prime} 45.8^{\prime \prime}$ & $30^{\circ} 50^{\prime} 45.8^{\prime \prime}$ & 2017.05 \\
\hline CX22 & $\begin{array}{l}\text { Chongzhou, } \\
\text { Sichuan }\end{array}$ & 573.0 & $103^{\circ} 39^{\prime} 58.3^{\prime \prime}$ & $30^{\circ} 43^{\prime} 46.5^{\prime \prime}$ & 2017.05 \\
\hline CX23 & Fuqing, Fujian & 122.0 & $119^{\circ} 23^{\prime} 15.2^{\prime \prime}$ & $25^{\circ} 44^{\prime} 28.1^{\prime \prime}$ & 2018.05 \\
\hline CX24 & Zhenba, Shanxi & 657.0 & $108^{\circ} 01^{\prime} 39.5^{\prime \prime}$ & $32^{\circ} 32^{\prime} 45.6^{\prime \prime}$ & 2018.06 \\
\hline
\end{tabular}


Epinephrine hydrochloride injection was purchased from Grand Pharmaceuticals (Beijing, China), and $0.9 \%$ sodium chloride injection was obtained from Sichuan Kelun Pharmaceuticals (Sichuan, China). Compound danshen tablets were obtained from Yunnan Baiyao Group Co., Ltd. (Yunnan, China).

Specific pathogen-free male and female Sprague-Dawley rats $(180-220$ g) were purchased from Chengdu Dashuo Experiment Animals (Chengdu, China). All rats were fed in a temperature-controlled facility with relative humidity of $65 \%$ and a $12-\mathrm{h}$ light-dark cycle.

\section{Blood-activating effect of CX extracted using different solvents}

\section{Sample preparation}

CX samples (250 g/batch) were ground into powder, soaked with $70 \%$ ethanol for $10 \mathrm{~h}$, and extracted eight times with $70 \%$ ethanol by seepage. The extracts were combined, and concentrated to a flow extract $(30 \mathrm{~mL})$ under reduced pressure, then dispersed with the appropriate amount of pure water. Then, they were extracted thrice with petroleum ether, dichloromethane, ethyl acetate or N-butanol, respectively. Extracts of each part were combined and concentrated under reduced pressure, and diluted to $250 \mathrm{~mL}$ with $0.5 \%$ carboxymethylcellulose sodium (CMC-Na) to obtain samples.

\section{Grouping and treatment of rats}

Rats were divided randomly into seven groups: blank; model; compound danshen tablets (CDT); test (four groups). Rats in the blank group did not receive any treatment; rats in the model group only replicated the blood stasis model without gavage drugs; rats in the CDT group and test groups replicated the blood stasis model and were gavaged the corresponding drugs. The specific treatment method was as follows: rats in the blank group and model group were administered pure water at $1 \mathrm{~mL} / \mathrm{kg} /$ day for 7 days. Rats in the CDT group were given CDTs at $1.8 \mathrm{~g} / \mathrm{kg} /$ day for 7 days. Rats in different test groups were given the corresponding extract at 1 $\mathrm{g} / \mathrm{kg} /$ day for 7 days, respectively. All treatments were given by gavage. Eight hours after gavage on day-7, rats in the model group, CDT group, and test groups were administered (s.c.) $0.1 \%$ epinephrine hydrochloride injection $(0.8 \mathrm{~mL} / \mathrm{kg})$ twice at an interval of $4 \mathrm{~h}$, whereas rats in the control group were administered subcutaneously (sc) $0.9 \%$ sodium chloride injection at the same dose as the test groups. Two hours after the first injection of $0.1 \%$ epinephrine hydrochloride, rats in all groups except for the control group were placed in an iced water bath for 5 min. Thirty minutes after gavage on day-8, rats in all groups were anesthetized with $10 \%$ chloral hydrate, and blood was collected from the abdominal aorta.

\section{Treatment and assessment of blood samples}

First, parameters from whole-blood samples were measured by an automatic hemorrheometer (SA-6000; Succeeder). Then, samples were centrifuged (3000 rpm for $30 \mathrm{~min}$ at room temperature), the supernatant separated, and analyzed.

\section{Determination of spectrum-effect relation- ship}

\section{Sample preparation}

The method of sample preparation was identical to that described as sample preparation in bloodactivating effect of $\mathrm{CX}$ extracted using different solvents.

\section{Grouping and treatment of rats}

Rats were divided randomly into 27 groups: blank; model; CDT; CX1-CX24. Rats in the CX1-CX24 groups were given the corresponding extracts at $1 \mathrm{~g} / \mathrm{kg} /$ day (bodyweight) for 7 days, respectively. Other treatments were identical to those described as grouping and treatment of rats in blood-activating effect of $\mathrm{CX}$ extracted using different solvents.

\section{Preparation of serum samples for HPLC}

CX powder $(100 \mathrm{~g})$ was soaked with $70 \%$ ethanol for $10 \mathrm{~h}$, and extracted eight times with $70 \%$ ethanol by seepage. The extracts were combined, and concentrated to a flow extract under reduced pressure, and diluted to $20 \mathrm{~mL}$ with the appropriate amount of $0.5 \%$ CMC-Na to obtain samples for pharmacodynamic studies.

Rats were divided randomly into 25 groups: blank; CX1-CX24. Rats in the blank group were administered $0.5 \%$ CMC-Na $\quad(1 \mathrm{~mL} / \mathrm{kg} /$ day bodyweight) for 3 days. CX1-CX24 groups were administered the corresponding pharmacodynamic sample at $1 \mathrm{~mL} / \mathrm{kg}$ bodyweight once a day for 3 days, respectively. Thirty minutes after gavage on day-3, rats in all groups were anesthetized with $10 \%$ chloral hydrate, and blood from the abdominal aorta was collected. After blood had coagulated, the supernatant was separated after centrifugation (3000 rpm for $10 \mathrm{~min}$ at room temperature). 
Methanol was added thrice to precipitate proteins. Then, the supernatant was aspirated and filtered through a $0.22-\mu \mathrm{m}$ membrane to yield serum samples for HPLC.

\section{Preparation of mixed standard solutions}

Appropriate amounts of ligustilide, senkyunolide A, senkyunolide I, coniferyl ferulate, and senkyunolide $\mathrm{H}$ were accurately weighed, and dissolved in methanol to prepare a series of stock solutions of different concentrations. Appropriate volumes of 5 stock solutions were transferred into the same volumetric flask; methanol was added to obtain mixed reference substance solutions of different concentrations.

\section{HPLC conditions}

HPLC was done on a LC-2012 system (Shimadzu) and chromatographic separation was carried on a SP-120-5 C18 column $(4.6 \mathrm{~mm} \times$ $250 \mathrm{~mm}, 5 \mu \mathrm{m})$ operated at $25{ }^{\circ} \mathrm{C}$. The mobile phase comprised methanol $(A)$ and water $(B)$, with a linear gradient of A: 0-40 min (30-85\%) [12]. The injection volume was $20 \mu \mathrm{L}$, and the flow rate was $1.0 \mathrm{~mL} / \mathrm{min}$. The detection wavelength of the HPLC fingerprint was $280 \mathrm{~nm}$.

\section{Validation of HPLC fingerprint method}

Precision, stability within $16 \mathrm{~h}$, and repeatability were used to assess the performance of instrument, stability of the target, and operational consistency, respectively [12].

\section{Similarity evaluation of fingerprints}

The HPLC chromatograms of 24 samples of serum from rats administered CX were imported into Similarity Evaluation System for Chromatographic Fingerprint of TCM (SESCF, Version 2004A) (Beijing, China), and generated reference standard fingerprint $(R)$, including 6 characteristic peaks (common peaks) by multipoint correction and peak matching, and the similarity values between the chromatogram of each serum from rats administered $\mathrm{CX}$ and the reference fingerprint were evaluated by this software.

\section{Statistical analysis}

Data from pharmacodynamic test are presented as mean \pm standard deviation (SD). Differences among different groups were analyzed by oneway ANOVA on SPSS 21.0 (IBM, Armonk, NY, USA). Bivariate correlation analyses between different hemorheology indices of $\mathrm{CX}$ and common peak areas were done using the grey correlation coefficient.

\section{RESULTS}

\section{Selected extraction solvent for blood- activating effect of $\mathrm{CX}$}

Compared with the model group, almost all hemorheology indices in the test groups were reduced. After treatment with $\mathrm{CX}$ extracted using different solvents (petroleum ether, dichloromethane, ethyl acetate, N-butanol), the hemorheology indices decreased compared with those in the model group. The effect of dichloromethane solvent was better than that of other solvents (Table 2).

\section{Blood-circulation effects of CX extracts}

Compared with the blank group, the hemorheology indices we assessed in the test groups were increased, which suggested that the iced water-induced coagulation model had been created successfully. After treatment with different $\mathrm{CX}$ extracts, the hemorheology indices changed compared with those in the model group (Table 3).

Table 2: Effect of CX extracted (using different solvents) on blood parameters

\begin{tabular}{|c|c|c|c|c|c|c|}
\hline \multirow[b]{2}{*}{ Group } & \multicolumn{3}{|c|}{ Viscosity of whole blood (mean \pm SD) } & \multirow[b]{2}{*}{$\begin{array}{c}\text { Plasma } \\
\text { viscosity } \\
\text { (mean } \pm \text { SD) }\end{array}$} & \multirow[b]{2}{*}{$\begin{array}{l}\text { Fibrinogen } \\
\text { (mean } \pm \text { SD) }\end{array}$} & \multirow{2}{*}{$\begin{array}{c}\text { Index of } \\
\text { erythrocyte } \\
\text { aggregation } \\
\text { (mean } \pm \text { SD) }\end{array}$} \\
\hline & $1\left(s^{-1}\right)$ & $50\left(s^{-1}\right)$ & $200\left(s^{-1}\right)$ & & & \\
\hline Control & $78.37 \pm 5.45$ & $10.10 \pm 0.57$ & $7.38 \pm 0.35^{\star *}$ & $3.52 \pm 0.11^{* *}$ & $7.75 \pm 0.23^{\star \star}$ & $10.34 \pm 0.57$ \\
\hline Model & $87.65 \pm 3.08$ & $11.38 \pm 0.45$ & $9.46 \pm 0.39$ & $4.96 \pm 0.21$ & $10.92 \pm 0.47$ & $11.17 \pm 1.33$ \\
\hline $\begin{array}{l}\text { Compound } \\
\text { danshen tablet }\end{array}$ & $84.13 \pm 2.33$ & $10.34 \pm 0.64$ & $7.73 \pm 0.40^{* *}$ & $3.73 \pm 0.28^{* *}$ & $8.20 \pm 0.62^{\star *}$ & $10.60 \pm 0.25$ \\
\hline Petroleum ether & $87.78 \pm 14.49$ & $11.29 \pm 0.34$ & $8.23 \pm 0.28^{*}$ & $4.66 \pm 0.10$ & $10.26 \pm 0.30$ & $10.82 \pm 0.18$ \\
\hline Dichloromethane & $87.29 \pm 2.26$ & $10.44 \pm 0.41$ & $7.79 \pm 0.24^{\star *}$ & $4.16 \pm 0.19^{\star *}$ & $9.15 \pm 0.42^{* *}$ & $10.67 \pm 0.36$ \\
\hline Ethyl acetate & $92.71 \pm 3.35$ & $10.73 \pm 0.31$ & $8.61 \pm 0.34$ & $4.67 \pm 0.18$ & $10.28 \pm 0.30$ & $10.98 \pm 0.50$ \\
\hline $\mathrm{N}$-butanol & $102.06 \pm 3.74^{*}$ & $10.84 \pm 0.53$ & $8.30 \pm 0.35^{\star}$ & $4.71 \pm 0.13$ & $10.37 \pm 0.35$ & $11.67 \pm 0.56$ \\
\hline
\end{tabular}


Table 3: Effect of CX extracts on blood parameters

\begin{tabular}{|c|c|c|c|c|c|c|}
\hline \multirow[b]{2}{*}{ Group } & \multicolumn{3}{|c|}{ Viscosity of whole blood (mean \pm SD) } & \multirow{2}{*}{$\begin{array}{c}\text { Plasma } \\
\text { viscosity } \\
\text { (mean } \pm \text { SD) }\end{array}$} & \multirow[b]{2}{*}{$\begin{array}{c}\text { Fibrinogen } \\
\text { (mean } \pm \text { SD) }\end{array}$} & \multirow{2}{*}{$\begin{array}{c}\text { Index of } \\
\text { erythrocyte } \\
\text { aggregation } \\
\text { (mean } \pm \text { SD) }\end{array}$} \\
\hline & $1\left(s^{-1}\right)$ & $50\left(s^{-1}\right)$ & $200\left(s^{-1}\right)$ & & & \\
\hline Blank & $24.16 \pm 1.31^{\star *}$ & $4.88 \pm 0.49^{* *}$ & $3.79 \pm 0.37^{* *}$ & $1.31 \pm 0.25^{\star *}$ & $2.97 \pm 0.26^{\star *}$ & $5.58 \pm 0.50^{* *}$ \\
\hline Model & $40.80 \pm 8.66$ & $6.27 \pm 1.99$ & $4.73 \pm 1.34$ & $1.79 \pm 0.15$ & $3.92 \pm 0.33$ & $7.81 \pm 0.40$ \\
\hline $\begin{array}{l}\text { Compound } \\
\text { danshen } \\
\text { tablets }\end{array}$ & $26.64 \pm 3.91^{* *}$ & $5.00 \pm 0.37^{\star *}$ & $4.04 \pm 0.35^{\star *}$ & $1.40 \pm 0.11^{\star *}$ & $2.97 \pm 0.29^{\star *}$ & $6.10 \pm 0.46^{\star \star}$ \\
\hline CX1 & $32.59 \pm 4.97^{\star \star}$ & $5.48 \pm 0.60^{\star *}$ & $4.26 \pm 0.43^{*}$ & $1.52 \pm 0.28^{* *}$ & $3.34 \pm 0.60^{* *}$ & $7.63 \pm 0.63$ \\
\hline CX2 & $30.19 \pm 3.36^{\star \star}$ & $5.49 \pm 0.33^{\star *}$ & $4.34 \pm 0.25$ & $1.40 \pm 0.14^{\star *}$ & $3.32 \pm 0.41^{\star *}$ & $6.96 \pm 0.68^{* *}$ \\
\hline $\mathrm{CX} 3$ & $31.62 \pm 3.86^{\star \star}$ & $5.60 \pm 0.55^{*}$ & $4.49 \pm 0.41$ & $1.44 \pm 0.19^{* *}$ & $3.21 \pm 0.40^{* *}$ & $6.98 \pm 0.67^{* *}$ \\
\hline $\mathrm{CX} 4$ & $29.42 \pm 3.16^{\star \star}$ & $5.44 \pm 0.37^{\star *}$ & $4.32 \pm 0.28$ & $1.46 \pm 0.13^{\star *}$ & $3.21 \pm 0.29^{* *}$ & $6.81 \pm 0.55^{\star \star}$ \\
\hline CX5 & $29.45 \pm 2.44^{\star \star}$ & $5.89 \pm 0.59$ & $4.76 \pm 0.55$ & $1.54 \pm 0.09^{*}$ & $3.22 \pm 0.32^{\star *}$ & $6.99 \pm 0.93^{* *}$ \\
\hline $\mathrm{CX6}$ & $27.84 \pm 2.38^{\star \star}$ & $5.25 \pm 0.40^{* *}$ & $4.19 \pm 0.36^{\star \star}$ & $1.61 \pm 0.52$ & $3.24 \pm 0.36^{\star *}$ & $6.14 \pm 0.68^{* *}$ \\
\hline CX7 & $29.36 \pm 2.29^{\star \star}$ & $5.62 \pm 0.47^{*}$ & $4.50 \pm 0.42$ & $1.44 \pm 0.15^{\star *}$ & $3.17 \pm 0.33^{\star *}$ & $6.56 \pm 0.62^{\star \star}$ \\
\hline CX8 & $28.22 \pm 2.82^{\star \star}$ & $5.56 \pm 0.20^{*}$ & $4.57 \pm 0.25$ & $1.50 \pm 0.22^{\star *}$ & $3.20 \pm 0.18^{\star *}$ & $5.85 \pm 0.51^{\text {** }}$ \\
\hline CX9 & $31.62 \pm 3.00^{\star *}$ & $5.62 \pm 0.42^{*}$ & $4.42 \pm 0.31$ & $1.51 \pm 0.18^{\star *}$ & $3.17 \pm 0.71^{* *}$ & $7.15 \pm 0.30^{*}$ \\
\hline CX10 & $31.41 \pm 6.03^{\star *}$ & $5.48 \pm 0.77^{\star *}$ & $4.30 \pm 0.57$ & $1.68 \pm 0.11$ & $3.74 \pm 0.25$ & $7.18 \pm 0.52^{*}$ \\
\hline CX11 & $27.71 \pm 4.35^{\star \star}$ & $5.16 \pm 0.4^{\star \star}$ & $4.10 \pm 0.37^{\star \star}$ & $1.43 \pm 0.22^{\star *}$ & $3.17 \pm 0.47^{\star *}$ & $6.75 \pm 0.72$ ** \\
\hline CX12 & $35.34 \pm 3.93^{\star \star}$ & $5.89 \pm 0.44$ & $4.57 \pm 0.32$ & $1.46 \pm 0.12^{\star *}$ & $3.21 \pm 0.27^{\star *}$ & $7.72 \pm 0.44$ \\
\hline CX13 & $31.51 \pm 6.26^{* *}$ & $5.39 \pm 0.76^{* *}$ & $4.21 \pm 0.55^{*}$ & $1.35 \pm 0.13^{* *}$ & $3.09 \pm 0.30^{* *}$ & $7.45 \pm 0.77$ \\
\hline CX14 & $30.66 \pm 3.35^{\star \star}$ & $5.39 \pm 0.42^{\star *}$ & $4.22 \pm 0.31^{\star}$ & $1.51 \pm 0.23^{\star *}$ & $3.14 \pm 0.17^{\star *}$ & $7.24 \pm 0.39^{*}$ \\
\hline CX15 & $30.35 \pm 5.77^{\star *}$ & $5.15 \pm 0.88^{\star *}$ & $4.01 \pm 0.67^{\star *}$ & $1.40 \pm 0.16^{\star *}$ & $3.08 \pm 0.35^{\star *}$ & $7.54 \pm 0.29$ \\
\hline CX16 & $35.77 \pm 4.19^{*}$ & $6.03 \pm 0.57$ & $4.69 \pm 0.44$ & $1.58 \pm 0.21^{*}$ & $3.46 \pm 0.46^{*}$ & $7.53 \pm 0.47$ \\
\hline CX17 & $28.07 \pm 4.81^{\star \star}$ & $5.42 \pm 0.32^{\star *}$ & $4.35 \pm 0.22$ & $1.52 \pm 0.13^{\star *}$ & $3.36 \pm 0.32^{\star *}$ & $6.15 \pm 0.51^{* *}$ \\
\hline CX18 & $36.28 \pm 4.80^{*}$ & $5.99 \pm 0.60$ & $4.63 \pm 0.43$ & $1.43 \pm 0.09^{* *}$ & $3.15 \pm 0.20^{* *}$ & $6.99 \pm 0.61^{* *}$ \\
\hline CX19 & $32.35 \pm 3.96^{\star \star}$ & $5.29 \pm 0.28^{* *}$ & $4.51 \pm 0.67$ & $1.44 \pm 0.12^{\star *}$ & $3.16 \pm 0.26^{\star *}$ & $6.79 \pm 0.69^{* *}$ \\
\hline CX20 & $31.53 \pm 4.77^{\star \star}$ & $5.77 \pm 0.53$ & $4.59 \pm 0.41$ & $1.34 \pm 0.12^{* *}$ & $3.09 \pm 0.24^{\star *}$ & $6.90 \pm 0.80$ ** \\
\hline CX21 & $30.42 \pm 6.37^{\star \star}$ & $5.43 \pm 0.81^{\star *}$ & $4.28 \pm 0.60$ & $1.64 \pm 0.36$ & $3.40 \pm 1.00^{* *}$ & $7.07 \pm 0.76^{\star *}$ \\
\hline CX22 & $32.15 \pm 2.89^{\star \star}$ & $5.67 \pm 0.61^{*}$ & $4.46 \pm 0.51$ & $1.60 \pm 0.32$ & $3.25 \pm 0.77^{\star *}$ & $7.44 \pm 0.46$ \\
\hline CX23 & $27.64 \pm 4.26^{\star \star}$ & $5.14 \pm 0.90^{* *}$ & $4.08 \pm 0.76^{\star *}$ & $1.48 \pm 0.26^{* *}$ & $3.07 \pm 0.23^{\star *}$ & $6.83 \pm 0.70^{* *}$ \\
\hline CX24 & $29.12 \pm 3.93^{\star \star}$ & $5.60 \pm 0.47^{*}$ & $4.49 \pm 0.37$ & $1.56 \pm 0.17^{*}$ & $3.34 \pm 0.18^{\star *}$ & $6.50 \pm 0.72^{* \star}$ \\
\hline
\end{tabular}

\section{Validation of the HPLC-fingerprint method}

Testing of precision, stability within $16 \mathrm{~h}$, and repeatability indicated that the relative standard deviation (RSD, $n=6$ ) of retention time and peak area value of 6 common peaks were $<5 \%$ (Table 4, Table 5 and Table 6, Table 7, Table 8, Table 9) [12]. Hence, our method was feasible for analyzing the HPLC fingerprints of CX extracts.

\section{HPLC fingerprints}

The HPLC fingerprints and the reference fingerprint of 24 batches rat serum were shown in Figure 1. And similarities among the HPLC chromatograms of these 24 samples of rat serum

Table 4: Relative retention time in precision test and reference standard fingerprints were analyzed. The RSD of the six common peak areas in the 24 samples of rat serum were $>35 \%$, indicating that the areas of each common peak in different serum samples varied widely.

The similarities in the HPLC chromatograms of 24 samples of rat serum were in the range 0.012-1.000. Similarities between the HPLC chromatograms of 24 samples and reference standard fingerprints were in range $0.174-0.98$.

\section{Identification of common peaks}

The common peaks were identified as senkyunolide I, senkyunolide $H$, senkyunolide $A$,

\begin{tabular}{lccccccc}
\hline Common peak & 1st & 2nd & 3rd & 4th & 5th & 6th & RSD/\% \\
\hline 1 & 0.568 & 0.570 & 0.568 & 0.567 & 0.570 & 0.563 & 0.46 \\
2 & 0.620 & 0.621 & 0.617 & 0.619 & 0.613 & 0.612 & 0.58 \\
3 & 1.000 & 1.000 & 1.000 & 1.000 & 1.000 & 1.000 & 0.00 \\
4 & 1.029 & 1.029 & 1.029 & 1.030 & 1.029 & 1.028 & 0.07 \\
5 & 1.161 & 1.160 & 1.158 & 1.165 & 1.162 & 1.155 & 0.30 \\
6 & 1.521 & 1.520 & 1.515 & 1.529 & 1.524 & 1.503 & 0.59 \\
\hline
\end{tabular}


Table 5: Relative peak area in precision test

\begin{tabular}{lccccccc}
\hline Common peak & 1st & 2nd & 3rd & 4th & 5th & 6th & RSD/\% \\
\hline 1 & 8.211 & 8.375 & 8.463 & 8.552 & 8.705 & 8.724 & 2.33 \\
2 & 2.143 & 2.157 & 2.068 & 2.043 & 2.041 & 2.060 & 2.47 \\
3 & 1.000 & 1.000 & 1.000 & 1.000 & 1.000 & 1.000 & 0.00 \\
4 & 0.256 & 0.256 & 0.251 & 0.247 & 0.252 & 0.270 & 3.07 \\
5 & 3.828 & 3.823 & 3.908 & 3.966 & 3.979 & 3.943 & 1.75 \\
6 & 1.862 & 1.708 & 1.774 & 1.764 & 1.901 & 1.688 & 4.72 \\
\hline
\end{tabular}

Table 6: Result of relative retention time in stability test

\begin{tabular}{lccccccc}
\hline Common peak & $\mathbf{0 h}$ & $\mathbf{2 h}$ & $\mathbf{4 h}$ & $\mathbf{6 h}$ & $\mathbf{8 h}$ & $\mathbf{1 6 h}$ & $\mathbf{R S D} / \%$ \\
\hline 1 & 0.770 & 0.770 & 0.770 & 0.771 & 0.770 & 0.769 & 0.06 \\
2 & 0.816 & 0.816 & 0.817 & 0.817 & 0.817 & 0.816 & 0.07 \\
3 & 1.000 & 1.000 & 1.000 & 1.000 & 1.000 & 1.000 & 0.00 \\
4 & 1.313 & 1.314 & 1.314 & 1.314 & 1.314 & 1.316 & 0.06 \\
5 & 1.517 & 1.518 & 1.518 & 1.519 & 1.518 & 1.522 & 0.10 \\
6 & 1.977 & 1.977 & 1.977 & 1.978 & 1.978 & 1.984 & 0.14 \\
\hline
\end{tabular}

Table 7: Relative peak area in stability test

\begin{tabular}{lccccccc}
\hline Common peak & $\mathbf{0 h}$ & $\mathbf{2 h}$ & $\mathbf{4 h}$ & $\mathbf{6 h}$ & $\mathbf{8 h}$ & $\mathbf{1 6 h}$ & $\mathbf{R S D} / \%$ \\
\hline 1 & 20.480 & 20.290 & 20.997 & 20.233 & 19.716 & 19.950 & 2.19 \\
2 & 5.809 & 6.047 & 5.799 & 6.076 & 5.582 & 5.657 & 3.43 \\
3 & 1.000 & 1.000 & 1.000 & 1.000 & 1.000 & 1.000 & 0.00 \\
4 & 2.057 & 1.976 & 2.140 & 2.052 & 1.919 & 1.969 & 3.93 \\
5 & 5.627 & 5.590 & 5.918 & 5.790 & 5.740 & 5.501 & 2.65 \\
6 & 5.601 & 5.900 & 5.935 & 5.733 & 5.430 & 5.531 & 3.57 \\
\hline
\end{tabular}

Table 8: Result of relative retention time in repeatability test

\begin{tabular}{lccccccc}
\hline Common peak & 1st & 2nd & 3rd & 4th & 5th & 6th & RSD/\% \\
\hline 1 & 0.556 & 0.557 & 0.549 & 0.561 & 0.556 & 0.566 & 0.99 \\
2 & 0.592 & 0.594 & 0.585 & 0.597 & 0.593 & 0.602 & 0.94 \\
3 & 1.000 & 1.000 & 1.000 & 1.000 & 1.000 & 1.000 & 0.00 \\
4 & 1.030 & 1.029 & 1.028 & 1.029 & 1.028 & 1.030 & 0.08 \\
5 & 1.163 & 1.158 & 1.158 & 1.161 & 1.155 & 1.165 & 0.30 \\
6 & 1.527 & 1.513 & 1.512 & 1.521 & 1.509 & 1.529 & 0.56 \\
\hline
\end{tabular}

Table 9: Relative peak area in repeatability test

\begin{tabular}{lccccccc}
\hline Common peak & 1st & 2nd & 3rd & 4th & 5th & 6th & RSD/\% \\
\hline 1 & 6.427 & 6.852 & 7.024 & 6.356 & 6.677 & 6.288 & 4.47 \\
2 & 1.870 & 1.836 & 1.834 & 1.934 & 1.921 & 1.828 & 2.51 \\
3 & 1.000 & 1.000 & 1.000 & 1.000 & 1.000 & 1.000 & 0.00 \\
4 & 0.283 & 0.280 & 0.293 & 0.286 & 0.286 & 0.271 & 2.59 \\
5 & 4.711 & 4.854 & 4.710 & 4.409 & 4.650 & 4.665 & 3.11 \\
6 & 1.653 & 1.587 & 1.576 & 1.606 & 1.570 & 1.672 & 2.64 \\
\hline
\end{tabular}

coniferyl ferulate, and ligustilide, respectively, by comparing the retention time and ultraviolet-

\section{Bivariate correlation analyses}

Bivariate correlation analyses (Table 7) showed that the contribution of the six common peaks to absorption curves of target peaks with those of standards (Figure 2).

the hemorheology indices of $\mathrm{CX}$ were in the order: peak 1 (senkyunolide I) $>$ peak 5 (ligustilide) > peak 3 (senkyunolide A) > peak 4 (coniferyl ferulate) $>$ peak 2 (senkyunolide $\mathrm{H})>$ peak 6. 


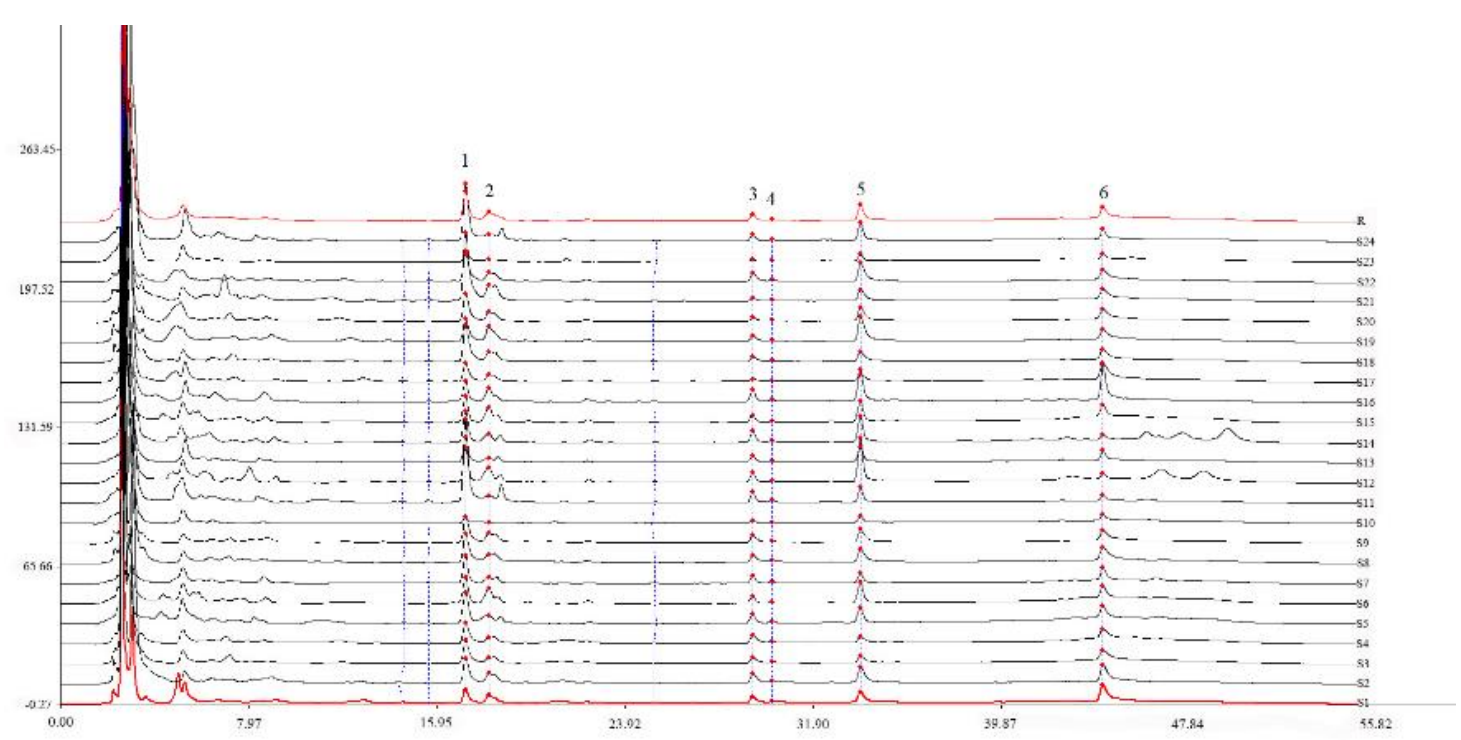

Figure 1: HPLC chromatograms of 24 samples of serum from rats administered CX1-CX24 extracts and the reference standard fingerprint including 6 common peaks (peak $1-6$ )

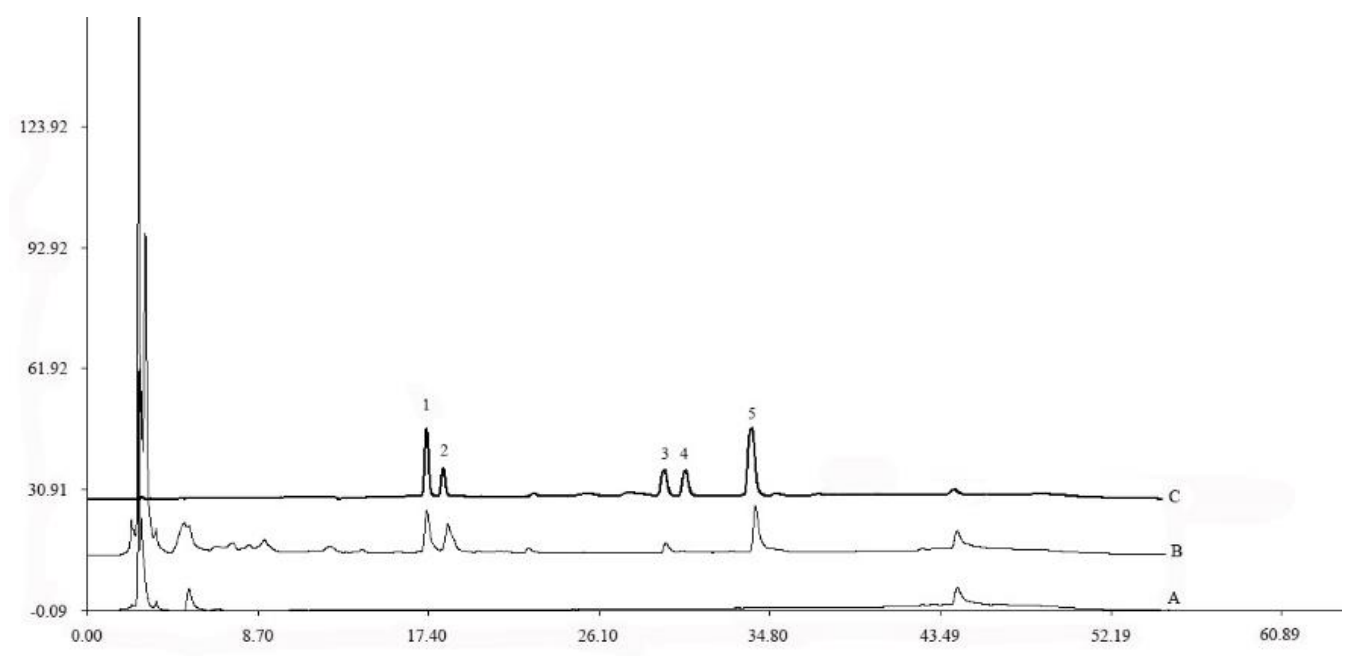

Figure 2: HPLC chromatograms of blank $(A)$, serum sample $(B)$ and mixed standards $(C)$. Peak 1: senkyunolide I; peak 2: senkyunolide $\mathrm{H}$; peak 3: senkyunolide $A$; peak 4: coniferyl ferulate; peak 5: ligustilide

Table 7: Correlation coefficient between different hemorheology indices of CX and six common peak areas

\begin{tabular}{|c|c|c|c|c|c|c|c|}
\hline \multirow{3}{*}{$\begin{array}{l}\text { Number of } \\
\text { common } \\
\text { peaks }\end{array}$} & \multicolumn{6}{|c|}{ Correlation coefficient } & \multirow{3}{*}{$\begin{array}{l}\text { Average of } \\
\text { correlation } \\
\text { coefficient }\end{array}$} \\
\hline & \multicolumn{3}{|c|}{ Viscosity of whole blood } & \multirow{2}{*}{$\begin{array}{l}\text { Plasma } \\
\text { viscosity }\end{array}$} & \multirow{2}{*}{ Fibrinogen } & \multirow{2}{*}{$\begin{array}{c}\text { Index of } \\
\text { erythrocyte } \\
\text { aggregation }\end{array}$} & \\
\hline & $1\left(s^{-1}\right)$ & $50\left(s^{-1}\right)$ & $200\left(s^{-1}\right)$ & & & & \\
\hline 1 & 0.7637 & 0.7699 & 0.7694 & 0.7511 & 0.7563 & 0.7582 & 0.7614 \\
\hline 2 & 0.6945 & 0.6999 & 0.7023 & 0.6992 & 0.7066 & 0.7072 & 0.7016 \\
\hline 3 & 0.7168 & 0.7316 & 0.7314 & 0.7189 & 0.7226 & 0.7213 & 0.7238 \\
\hline 4 & 0.7140 & 0.7291 & 0.7296 & 0.6962 & 0.7066 & 0.7175 & 0.7155 \\
\hline 5 & 0.7365 & 0.7370 & 0.7385 & 0.7209 & 0.7239 & 0.7288 & 0.7309 \\
\hline 6 & 0.6692 & 0.6792 & 0.6859 & 0.6626 & 0.6719 & 0.6678 & 0.6727 \\
\hline
\end{tabular}

\section{DISCUSSION}

Clinical studies have shown that cardiovascular diseases and cerebrovascular diseases are related mostly to blood stasis, so improving blood stasis would be a rational approach. Reports $[13,14]$ have shown that ligustilide, senkyunolide 
I, senkyunolide $H$, senkyunolide $A$, ferulic acid and ligustrazine can improve blood stasis, respectively. However, not all of these compounds have been reported to be in CX or in the body fluids of animals. Therefore, there was insufficient evidence in the previous studies to demonstrate that these components are the active ingredients of $\mathrm{CX}$.

Subcutaneous injection of epinephrine and an iced water bath is the most commonly used method to replicate acute blood stasis [15-17]. Water temperature, the injection site, and the time blood is collected have a considerable influence on experimental results. Epinephrine is a vasoactive drug, which causes the death of rats by increasing the blood pressure suddenly when injected close to the head or injected into a blood vessel by mistake. Therefore, injecting epinephrine accurately and mastering the time to start blood collection are the key to successful modeling.

Thirty minutes after the last gavage was selected as the time to start blood collection because there were no more peaks after $30 \mathrm{~min}$. In this work, methanol was selected as the organic mobile phase by comparing the shape and separation of the peak.

The spectrum - effect relationship can be used to determine the main medicinal ingredients of a target drug based on the contribution of its different components. In this study, we studied the active part of $\mathrm{CX}$ for blood - activating, and compared the blood - activating effects and serum HPLC fingerprints of CX from different origins, then evaluated the spectrum - effect relationship of them by grey correlation coefficient. The greater the correlation coefficient, the greater was the contribution of the corresponding peak to the blood-circulation activity of CX extracts [18]. We revealed that the contributions of six common peaks to the bloodcirculation activity of $\mathrm{CX}$ extracts were in the order: peak 1 (senkyunolide I) $>$ peak 5 (ligustilide) > peak 3 (senkyunolide $A$ ) > peak 4 (coniferyl ferulate) > peak 2 (senkyunolide $\mathrm{H}$ ) > peak 6. Compared with the HPLC fingerprints of medicinal materials, serum HPLC fingerprints can better explain the effect of different ingredients on drug efficacy. This study revealed the blood promoting effect of 5 active ingredients through systematic research. Combined with the previous reports, senkyunolide I, ligustilide, senkyunolide A, coniferyl ferulate and senkyunolide $\mathrm{H}$ may be the medicinal material basis of CX for blood - activating.

\section{CONCLUSION}

In this study, we investigated the spectrum-effect relationship between the blood-circulation activity and serum HPLC fingerprints of CX extracts for the first time. Our study suggested that ligustilide, senkyunolide A, coniferyl ferulate, senkyunolide $\mathrm{H}$ and senkyunolide I helped to improve blood circulation in rats. Our study provides scientific justification for using $\mathrm{CX}$ to remove blood stasis.

\section{DECLARATIONS}

\section{Acknowledgement}

This work was supported by Characteristics, Standards and Digitalization of Common Genuine Medicinal Materials and Their Production Areas (no. 2015FY111500-140) organized by the Ministry of Science and Technology of the People's Republic of China, "Xinglin Scholar" Academic Backbone Project for Discipline Talents Scientific Research Enhancement (no. XSGG-2019023) and "Xinglin Scholars" Younger Scholars Project for Discipline Talents Scientific Research Enhancement (no. QNXZ2019024) organized by Chengdu University of Traditional Chinese Medicine, Research on Modernization of Traditional Chinese Medicine (no. 2019YFC1712302) organized by National Administration of Traditional Chinese Medicine.

\section{Data availability}

The data used to support the findings of this study are available from the corresponding author upon request.

\section{Conflict of interest}

No conflict of interest is associated with this work.

\section{Contribution of authors}

We declare that this work was done by the authors named in this article and all liabilities pertaining to claims relating to the content of this article will be borne by the authors.

\section{Open Access}

This is an Open Access article that uses a funding model which does not charge readers or their institutions for access and distributed under the terms of the Creative Commons Attribution License (http://creativecommons.org/licenses/by/

Trop J Pharm Res, April 2021; 20(4): 764 
4.0) and the Budapest Open Access Initiative (http://www.budapestopenaccessinitiative.org/rea d), which permit unrestricted use, distribution, and reproduction in any medium, provided the original work is properly credited.

\section{REFERENCES}

1. Chinese Pharmacopoeia, Chinese Pharmacopoeia Commission, China Medical Science and Technology Press, Beijing, China, 2020.

2. Jiang $W$, Chen $X$, Hu N, Zhao M, Liu XY. Study on the effects of Ligusticum wallichii with different proportion of Angelica sinensis on the contents of endogenous substances in migraine rats. Prog Mod Biomed 2017; 17(5): 830-834.

3. Mei Q, Li QS, Zhang J, Zeng XF. Experimental study on effect of combination of dandgui and chuanxiong in blood lipid and coronary artery tissue structure. J Hubei Univ Chin Med 2015;17(5): 47-49.

4. Wang $S X$, Research on treatment of internal diseases of blood circulation. J Pract Trad Chin Internal Med 2015; 29(4): 59-60.

5. Li HX, Ding MY, Yu JY. Separation and identification of the phthalic anhydride derivatives of ligusticum Chuanxiong Herb by GC-MS, TLC, HPLC-DAD, and HPLC-MS. J Chromatogr Sci 2002; 40(3): 156-161.

6. Li HX, Ding MY, LV K, Yu JY. Determination of the active ingredients in Chuanxiong by HPLC, HPLC-MS, and ElMS. J Liq Chromatogr R T 2001; 24(13): 2017-2031.

7. Yuan $Y$, Lin $X$, Feng $Y, X u D S$, Wang $Y H$. In vivo transmigration of anti-migrainous compounds from Ligusticum chuanxiong Hort. China Acad J 2010; 45(9): 694-697.

8. Lin H. Protective effect of senkyunolide $A$ against rats cerebral ischemia-reperfusion injury. J North Pharm 2016; 13(4): 114-115.

9. Kong $W J$, Zhao $Y L$, Shan $L M$, Xiao $X H$, Guo $W Y$. Investigation on the spectrum-effect relationships of $E t$ OAC extract from Radix Isatidis based on HPLC fingerprints and microcalorimetry. J Chromatogr $B$ Analyt Technol Biomed Life Sci 2008; 871(1): 109-114.
10. Kong WJ, Zhao YL, Xiao XH, Wang JB, Li HB, Li ZL, Jin $C$, Liu Y. Spectrum-effect relationships between ultraperformance liquid chromatography fingerprints and anti-bacterial activities of Rhizoma coptidis. Anal Chim Acta 2009; 634(2): 279-285.

11. National Research Council of the National Academy of Science, Guide for the Care and Use of Laboratory Animals: Eight Edition. National Academies Press: Washington, DC, 2010.

12. Jiang $Y B$, Zhong $M$, Gou $Y$, Peng $W$, Zhou J, Wu PE, Ma $Y Y$. Development of a more specific and accurate multiple reaction monitoring method based on GCEI/MS/MS for simultaneously monitoring and determining 34 kinds of pesticides in Qianjinzhidai pills. J Chromatogr B Analyt Technol Biomed Life Sci 2015; 983-984, 47-54.

13. Zhu M, Tang YP, Duan JA, Guo JM, Guo S, Su SL, Shang EX, Qian DW, Ding AW. Roles of paeoniflorin and senkyunolide I in SiWu decoction on antiplatelet and anticoagulation activities. J Sep Sci 2010; 33(21): 3335-3340.

14. Liu X, Cheng YQ, Cui XB, Li MC. Spectrum-effect study on the protective efficacy of Ligusticum Chuanxiong Hort. on myocardial ischemia. China Pharma 2016; 25(15): 9-12.

15. Song CC, Wang ZB, Su B, Guo YD, Gao Y, Zuo ZP, Jin $J J$. Study on commonly used rat model of blood stasis syndrome. J Beijing Univ Trad Chin Med 2014; 37(2): 94-98.

16. Zhao $Y, Y u X$, Shi $L L$, Chen BN, Wang SH, Du GH. Effects of the effective components group of Xiaoshuantongluo formula on rat acute blood stasis model. Acta Pharmaceutica Sinica 2012; 47(5): 604608.

17. Li WX, Tang YP, Guo JM, Huang MY, Qian DW, Duan $J A$. Comparative assessing the effects of angelica root and chuanxiong on the hemorheology and the blood coagulation function in acute blood stasis rats. Chin $\mathrm{J}$ Integr Trad Western Med 2012; 32(6): 806-810.

18. Sun $L Q$, Ding $X P$, Qi J, Yu H, He SA, Zhang J, Ge $H X$, $Y u B Y$. Antioxidant anthocyanins screening through spectrum-effect relationships and DPPH-HPLC-DAD analysis on nine cultivars of introduced rabbiteye blueberry in China. Food Chem 2012; 132(2): 759-765. 